\title{
"Just Getting a Cup of Coffee"- Considering Best Practices for Patients' Movement off the Hospital Floor
}

\author{
Sara Stream, MD ${ }^{1 *}$, David Alfandre, MD, MSPH ${ }^{1,2}$
}

'Section of Hospital Medicine, Medical Service, VA New York Harbor Healthcare System, Manhattan Campus, Department of Medicine, NYU School of Medicine, New York, New York; ${ }^{2}$ National Center for Ethics in Health Care, US Department of Veterans Affairs, Washington, DC.

\section{1}

58-year-old man with a remote history of endocarditis and no prior injection drug use was admitted to the inpatient medicine service with fever and concern for recurrent endocarditis. A transthoracic echocardiogram was unremarkable and the patient remained clinically stable. A transesophageal echocardiogram (TEE) was scheduled for the following morning, but during nursing rounds, the patient was missing from his room. Multiple staff members searched for the patient and eventually located him in the hospital lobby drinking a cup of coffee purchased from the cafeteria. Despite his opposition, he was escorted back to his room and advised to not leave the floor again. Later that day, the patient became frustrated and left the hospital before his scheduled TEE. He was subsequently lost to follow-up.

\section{INTRODUCTION}

Patients are admitted to the hospital based upon a medical determination that the patient requires acute observation, evaluation, or treatment. Once admitted, healthcare providers may impose restrictions on the patient's movement in the hospital, such as restrictions on leaving their assigned floor. Managing the movement of hospitalized patients poses significant challenges for the clinical staff because of the difficulty of providing a treatment environment that ensures safe and efficient delivery of care while promoting patients' preferences for an unrestrictive environment that respects their independence. ${ }^{1,2}$ Broad limits may make it easier for staff to care for patients and reduce concerns about liability, but they may also frustrate patients who may be medically, psychiatrically, and physically stable and do not require stringent monitoring (eg, completing a course of intravenous antibiotics or awaiting placement at outside facilities).

Although this issue has broad implications for patient safety and hospital liability, authoritative guidance and evidence-based literature are lacking. Without clear guidelines, healthcare staff members are likely to spend more time in managing each individual request to leave the floor because they do not have a systematic strategy for making fair and consistent decisions. Here, we describe the patient and insti-

*Corresponding Author: Sara Stream, MD; E-mail: Sara.Stream@nyulangone. org; Phone: 212-951-6868

Published online first June 11, 2019

Received: December 19, 2018; Revised: April 2, 2019; Accepted: April 9, 2019

๑) 2019 Society of Hospital Medicine DOI 10.12788/jhm.3227 tutional considerations when managing patient movement in the hospital. We refer to "patient movement" specifically as a patient's choice to move to different locations within the hospital, but outside of their assigned room and/or floor. This does not include scheduled, supervised ambulation activities, such as physical therapy.

\section{POTENTIAL CONSEQUENCES OF LIBERALIZING AND RESTRICTING INPATIENT MOVEMENT}

Practices that promote patient movement offer significant benefits and risks. Enhancing movement is likely to reduce the "physiologic disruption"3 of hospitalization while improving patients' overall satisfaction and alignment with patientcentered care. Liberalized movement also promotes independence and ambulation that reduces the rate of physical deconditioning. ${ }^{4}$

Despite theoretical benefits, hospitals may be more concerned about adverse events related to patient movement, such as falls, the use of illicit substances, or elopement. Given that hospitals may be legally ${ }^{5}$ and financially responsible ${ }^{6}$ for adverse events associated with patient movement, allowances for off-floor movement should be carefully considered with input from risk management, physicians, nursing leadership, patient advocates, and hospital administration.

Additionally, unannounced movement off the floor may interfere with timely and efficient care by causing lapses in monitoring, such as cardiac telemetry, medication administration, and scheduled diagnostic tests. In these situations, the risks of patient absence from the floor are significant and may ultimately negate the benefits of continued hospitalization by compromising the central elements of patient care.

\section{CLINICAL CONSIDERATIONS}

Patients' requests to leave the hospital floor should be evaluated systemically and transparently to promote fair, high-value care. First, a request for liberalized movement should prompt physicians that the patient may no longer require hospitalization and may be ready for the transition to outpatient care. ${ }^{8}$ If the patient still requires inpatient care, then the medical practitioner should make a clinical determination if the patient is medically stable enough to leave their hospital floor. The provider should first identify when the liberalization of movement would be universally inappropriate, such as in patients who are physically unable to ambulate without posing significant 


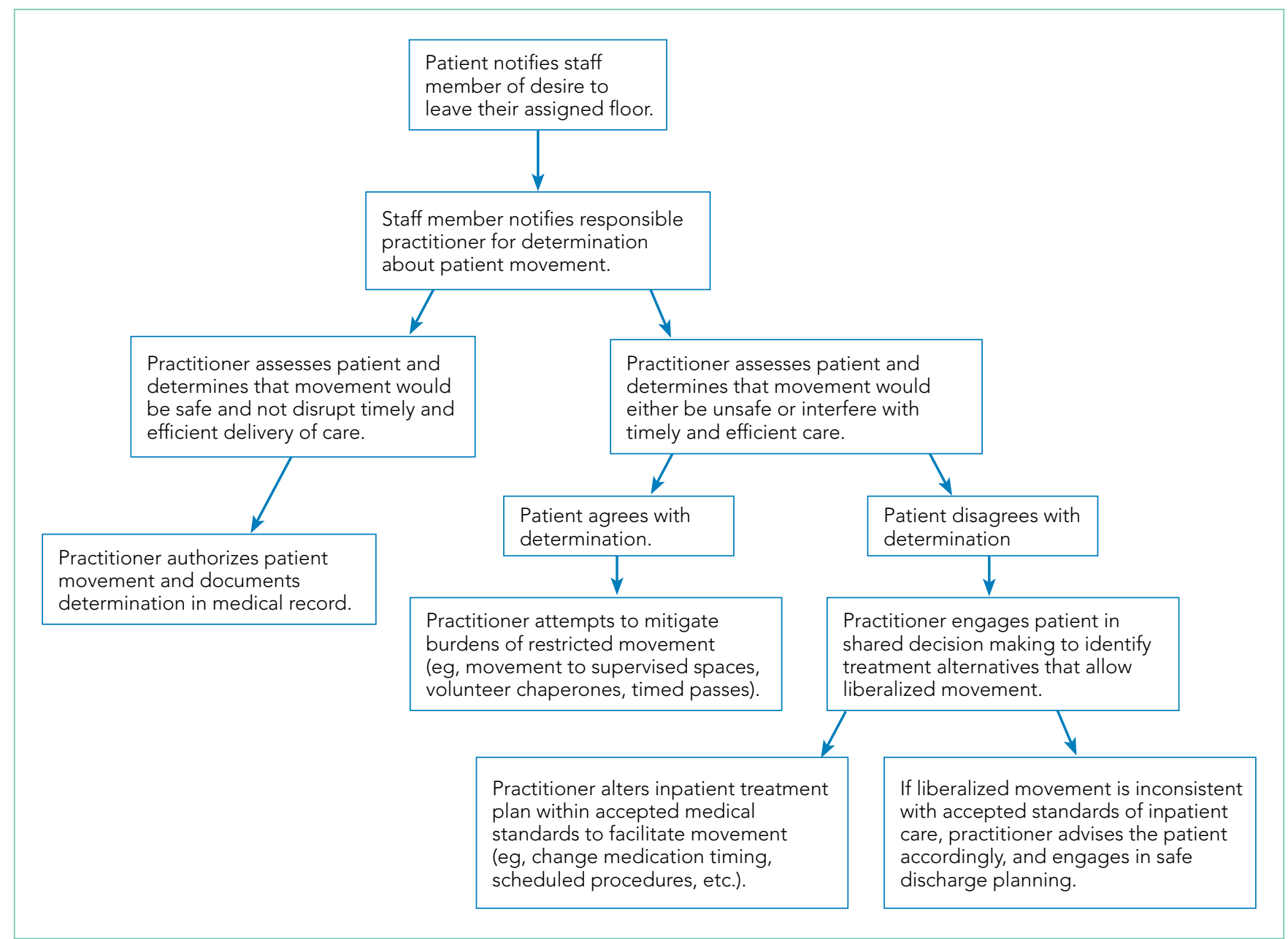

FIG 1. Sample Flowchart for Practitioners to Manage Patients' Requests for Movement

harm to themselves. This includes an accidental fall (usually while walking ${ }^{5}$ ), which is one of the most commonly reported adverse events in an inpatient setting. ${ }^{9}$ Additionally, patients with significant cognitive impairments or those lacking in decision-making capacity may be restricted from leaving their floors unescorted, as they are at a higher risk of disorientation, falls, and death. ${ }^{10}$

In determining movement restrictions for patients in isolation, hospitals should refer to the existing guidelines on isolation precautions for the transmission of communicable infections ${ }^{11,12}$ and neutropenic precautions. ${ }^{13}$ Additionally, movement restriction for patients who are isolated after screening positive for certain drug-resistant organisms (eg, methicillin-resistant Staphylococcus aureus and vancomycin-resistant enterococci) is controversial and should be evaluated based on the available medical evidence and standards. ${ }^{14-16}$

When making a risk-benefit determination about movement, providers should also assess the intent and the potentially unmet needs behind the patient's request. Patient-centered reasons for enhanced freedom of movement within the hospital include a desire for exercise, greater food choice, and visiting with loved ones, all of which can enable patients to manage the well-known inconveniences and stresses of hospitalization.
In contrast, there may be concerns for other intentions behind leaving assigned floors based on the patient's clinical history, such as the surreptitious use of illicit substances or attempts to elope from the hospital. Advising restriction of movement is justifiable if there is a significant concern for behavior that undermines the safe delivery of care. In patients with active substance use disorders, the appropriate treatment of pain or withdrawal symptoms may better address the patients' unmet needs, but a lower threshold to restrict movement may be reasonable given the significant risks involved. However, given the widespread stigmatization of patients with substance use disorders ${ }_{1}^{17}$ institutional policy and clinicians should adhere to systematic, transparent, and consistent risk assessments for all patients in order to minimize the potential for introducing or exacerbating disparities in care.

\section{ETHICAL CONSIDERATIONS}

In order to work productively with admitted patients, strong practices honor patients' autonomy by specifying when and how patients are informed of the institution's expectations about and limitations to inpatient movement. For example, emergency room patients were less likely to elope when treatment expectations were established at the time of presenta- 
tion by giving them information about wait times and triage protocol. ${ }^{18}$ Similarly, by preemptively discussing reasonable restrictions on movement as a part of informed consent for inpatient admission, physicians can establish patients' expectations early in the admission process and foster a therapeutic alliance on the basis of the shared goals of safe and timely care.

Patients may request or even demand to leave the floor after a healthcare provider has determined that doing so would be unsafe and/or undermine the timely and efficient delivery of care. In these cases, shared decision-making (SDM) can help identify acceptable solutions within the identified constraints. SDM combines the physicians' experience, expertise, and knowledge of medical evidence with patients' values, needs, and preferences for care..$^{19}$ If patients continue to request to leave the floor after the restriction has been communicated, physicians should discuss whether the current treatment plan should be renegotiated to include a relatively minor modification (eg, a change in the timing or route of administration of medication). If inpatient care cannot be provided safely within the patient's preferences for movement and attempts to accommodate the patient's preferences are unsuccessful, then a shift to discharge planning may be appropriate. A summary of this decision process is outlined in the Figure.

Of note, physicians' decisions about the appropriateness of patient movement could conflict with the existing institutional procedures or policies (eg, a physician deems increased patient movement to carry minimal risks, while the institution seeks to restrict movement due to concerns about liability). For this reason, it is important for clinicians to participate in the development of institutional policy to ensure that it reflects the clinical and ethical considerations that clinicians apply to patient care. A policy designed with input from relevant stakeholders across the institution including legal, nursing, physicians, administration, ethics, risk management, and patient advocates can provide expert guidance that is based on and consistent with the institution's mission, values, and priorities. ${ }^{20}$

\section{ENHANCING SAFE MOVEMENT}

In mitigating the burdens of restriction on movement, hospitals may implement a range of options that address patients' preferences while maintaining safety. Given the potential consequences of liberalized patient movement, it may be prudent to implement these safeguards as a compromise that addresses both the patients' needs and the hospital's concerns. These could include an escort for off-floor supervision, timed passes to leave the floor, or volunteers purchasing food for patients from the cafeteria. Creating open, supervised spaces within the hospital (eg, lounges) may also help provide the respite patients need, but in a safe and medically structured environment.

\section{CONCLUSION}

Returning to the introductory case example, we now present an alternative outcome in the context of the practices described above. On the morning of the scheduled TEE, a nurse noted that the patient was missing from his room. Before the staff began searching for the patient, they consulted the medical record which included the admission discussion and agreement to expectations for inpatient movement. The record also included an informed consent discussion indicating the minimal risks of leaving the floor, as the patient could ambulate independently and had no need for continuous monitoring. Finally, a physician's order authorized the patient to be off the floor until $10 \mathrm{AM}$. The patient returned to his room at 9:45 AM and underwent a normal TEE, after which he was discharged home with outpatient follow-up.

The above scenario highlights the benefits of a comprehensive framework for patient movement practices that are transparent, fair, and systematic. Explicitly recognizing competing institutional and patient perspectives can prevent conflict and promote high-quality, safe, efficient, patient-centered care that only restricts the patient's movement under specified and justifiable conditions. In developing strong hospital practices, institutions should refer to the relevant clinical and ethical standards and draw upon their institutional resources in risk management, clinical staff, and patient advocates.

\section{Acknowledgments}

The authors thank Dr. Neil Shapiro and Dr. David Chuquin for their constructive reviews of prior versions of this manuscript.

Disclosures: The authors have no financial conflicts of interest to disclose.

Disclaimer: The views expressed in this article are those of the authors and do not necessarily reflect the position or policy of the US Department of Veterans Affairs, the US Government, or the VA National Center for Ethics in Health Care.

\section{References}

1. Smith T. Wandering off the floors: safety and security risks of patient wandering. PSNet Patient Safety Network. Web M\&M 2014. Accessed December 4, 2017.

2. Douglas $\mathrm{CH}$, Douglas MR. Patient-friendly hospital environments: exploring the patients' perspective. Health Expect. 2004;7(1):61-73. https://doi. org/10.1046/j.1369-6513.2003.00251.x.

3. Detsky AS, Krumholz HM. Reducing the trauma of hospitalization. JAMA. 2014;311(21):2169-2170. https://doi.org/10.1001/jama.2014.3695

4. Covinsky KE, Pierluissi E, Johnston CB. Hospitalization-associated disability: "She was probably able to ambulate, but I'm not sure." JAMA. 2011;306(16):1782-1793. https://doi.org/10.1001/jama.2011.1556.

5. Oliver D, Killick S, Even T, Willmott M. Do falls and falls-injuries in hospital indicate negligent care-and how big is the risk? A retrospective analysis of the NHS Litigation Authority Database of clinical negligence claims, resulting from falls in hospitals in England 1995 to 2006. Qual Saf Health Care. 2008;17(6):431-436. https://doi.org/10.1136/qshc.2007.024703.

6. Mello MM, Chandra A, Gawande AA, Studdert DM. National costs of the medical liability system. Health Aff (Millwood). 2010;29(9):1569-1577. https:// doi.org/10.1377/hlthaff.2009.0807.

7. Dressler R, Dryer MM, Coletti C, Mahoney D, Doorey AJ. Altering overuse of cardiac telemetry in non-intensive care unit settings by hardwiring the use of American Heart Association guidelines. JAMA Intern Med. 2014;174(11):1852-1854. https://doi.org/10.1001/jamainternmed.2014.4491.

8. Conley J, O'Brien CW, Leff BA, Bolen S, Zulman D. Alternative strategies to inpatient hospitalization for acute medical conditions: a systematic review. JAMA Intern Med. 2016;176(11):1693-1702. https://doi.org/10.1001/jamainternmed.2016.5974.

9. Halfon P, Eggli Y, Van Melle G, Vagnair A. Risk of falls for hospitalized patients: a predictive model based on routinely available data. J Clin Epidemiol. 2001;54(12):1258-1266. https://doi.org/10.1016/S0895-4356(01)00406-1

10. Rowe M. Wandering in hospitalized older adults: identifying risk is the first step in this approach to preventing wandering in patients with de- 
mentia. Am J Nurs. 2008;108(10):62-70. https://doi.org/10.1097/01 NAJ.0000336968.32462.c9.

11. Siegel JD, Rhinehart E, Jackson M, Chiarello L. Health care infection contro practices advisory C. 2007 Guideline for isolation precautions: preventing transmission of infectious agents in health care settings. Am J Infect Control. 2007;35(10 Suppl 2):S65-S164. https://doi.org/10.1016/j.ajic.2007.10.007

12. Ito $Y$, Nagao $M$, linuma $Y$, et al. Risk factors for nosocomial tuberculosis transmission among health care workers. Am J Infect Control. 2016;44(5):596-598 https://doi.org/10.1016/j.ajic.2015.11.022.

13. Freifeld AG, Bow EJ, Sepkowitz KA, et al. Clinical practice guideline for the use of antimicrobial agents in neutropenic patients with cancer: 2010 update by the infectious diseases society of america. Clin Infect Dis. 2011;52(4):e56-e93. https://doi.org/10.1093/cid/ciq147

14. Martin EM, Russell D, Rubin Z, et al. Elimination of routine contact precautions for endemic methicillin-resistant staphylococcus aureus and vancomycin-resistant enterococcus: a retrospective quasi-experimental study. Infect Control Hosp Epidemiol. 2016;37(11):1323-1330. https://doi.org/10.1017/ ice.2016.156

15. Morgan DJ, Murthy R, Munoz-Price LS, et al. Reconsidering contact precautions for endemic methicillin-resistant Staphylococcus aureus and vancomy- cin-resistant Enterococcus. Infect Control Hosp Epidemiol. 2015;36(10):11631172. https://doi.org/10.1017/ice.2015.156.

16. Fatkenheuer G, Hirschel B, Harbarth S. Screening and isolation to control meticillin-resistant Staphylococcus aureus: sense, nonsense, and evidence. Lancet. 2015;385(9973):1146-1149. https://doi.org/10.1016/S01406736(14)60660-7

17. van Boekel LC, Brouwers EP, van Weeghel J, Garretsen HF. Stigma among health professionals towards patients with substance use disorders and its consequences for healthcare delivery: systematic review. Drug Alcohol Depend. 2013;131(1-2):23-35. https://doi.org/10.1016/j.drugalcdep.2013.02.018.

18. Handel DA, Fu R, Daya M, York J, Larson E, John McConnell K. The use of scripting at triage and its impact on elopements. Acad Emerg Med. 2010;17(5):495-500. https://doi.org/10.1111/j.1553-2712.2010.00721.x.

19. Barry MJ, Edgman-Levitan S. Shared decision making-pinnacle of patient-centered care. N Engl J Med. 2012;366(9):780-781. https://doi. org/10.1056/NEJMp1109283.

20. Donn SM. Medical liability, risk management, and the quality of health care. Semin Fetal Neonatal Med. 2005;10(1):3-9. https://doi.org/10.1016/j. siny.2004.09.004 